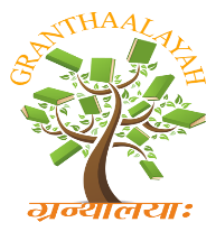

$$
\begin{gathered}
\text { INTERNATIONAL JOURNAL OF RESEARCH - } \\
\text { GRANTHAALAYAH } \\
\text { A knowledge Repository }
\end{gathered}
$$

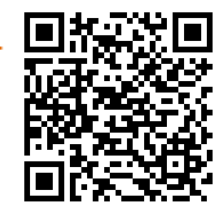

\title{
ATMOSPHERIC POLLUTION AND CLIMATE CHANGE
}

\author{
Abida Shamim Qureshi \\ Holkar Science College, Indore (M.P.)
}

\begin{abstract}
The whole world is on the terrifying cross-roads of global environmental threat. Last several years, particularly the last two years dominated the headlines about the serious threat climate change posed to the world. The more frequent severe weather conditions which result from climate change or global warming in the form of storms, tornadoes, tsunamis, floods, droughts, rising sea level and such other catastrophes have raised the economic cost of the natural disasters. The result, it appears, is beyond our control and, perhaps, there is no immediate answer to it.
\end{abstract}

Keywords:

Global-Warming, Climate, Weather, Environment.

\section{INTRODUCTION}

The greenhouse effect plays a crucial role in maintaining a life-sustaining environment on earth. If there is no greenhouse effect, i.e. there are no greenhouse gases existing in our atmosphere, the situation would be different. The temperature of the earth is determined by the amount of incoming solar radiation that reaches and heats the surface. The greenhouse gases in the atmosphere allow the sun's ultraviolet radiation to penetrate and warm the earth, and they absorb the infrared energy that radiates back into the atmosphere. By blocking the escape of this radiation, these gases effectively form a blanket around the earth. Greenhouse gases makeup only the earth, thereby trapping the heat and keeping the planet warmer than it would be otherwise.

The greenhouse gases which contribute significantly to the warming of the globe are also responsible in interfering in the global climate. Thus, the concentration of greenhouse gases, namely carbon dioxide, methane, nitrous oxide and certain other heat trapping gases contribute in a significant manner to the changes that occur in the atmospheric climate. Carbon dioxide is produced when fossil fuels are burnt and with the rapid depletion of forest cover, the effect of carbon dioxide is further intensified. Methane and nitrous oxide are generally used in agricultural practices and the release of such gases causes certain effects on the lands and land use and also, most importantly, chlorofluorocarbons (CFCs) and other gases which have the capacity to trap the heat also account for changes in the climate.

\section{EMISSION OF CARBON DIOXIDE}

Global emissions of carbon dioxide - the prime greenhouse gas added to the atmosphere as a direct result of human activity - amounted to 26.4 billion metric tons per year, of which 84 percent $(22.3$ billion metric tons) was from industrial activity. Emissions from industrial activity have climbed 
38 per cent over the past 20 years. The United States continues to be the largest source of industrial emissions of carbon dioxide, accounting for nearly 22 per cent of global emissions followed by China, Russia and Japan which account for 11.9,9.4 and 5 per cent of emissions, respectively. The European Union countries account for 13 per cent of the global emissions whereas the developed countries of the organization for Economic Cooperation and Development (OECD) account for 44.7 percent.

This rapid increase in the emissions of carbon dioxide in the developing countries is attributed to the expansion of industrial activities on a massive scale. With the shift in stand of the economies and opting for the industrial growth which replaced the agrarian sector saw the manufacture of certain items like refrigerators, air conditioners, etc. which contribute to the emission of such gases. India which is placed with China, both of which are on major expansion process in the industrial sector, coupled with high population growth are expected to contribute significantly in the emission of carbon dioxide in the next two decades. It is also expected that by the end of this decade both the countries may account for more emissions of carbon dioxide than the OECD countries. The past record and the present day emissions of carbon dioxide confirms the position that in this century itself we are going to witness a significant change. The latest World Bank Report titled 'India's Carbon Foot print', which outlines the massive increase in carbon dioxide emissions due to fast development, says that emissions in the country are set to increase to 4.5 billion tons by 2031 from the current 1.1 billion tons. The report says that the bulk 53 per cent would be from grid supply electricity, followed by industries 26 per cent, transport 16 per cent and captive power plants by 5 per cent.

\section{CONVENTION ON THE CLIMATE CHANGE}

Concerned with the fact that the human activities have been substantially increasing the atmospheric concentrations of greenhouse gases, that these increases enhance the natural greenhouse effect and that this will result on average in an additional warming of the earth's surface and atmosphere and may adversely affect natural ecosystems and humankind, the United Nations adopted a Framework Convention on Climate Change which was opened for signature at the Rio Summit in 1992 where 155 governments signed the Convention and since then over 160 governments have ratified or otherwise committed themselves to this convention. Their purpose was to stabilize greenhouse gas concentrations in the atmosphere at a level that would prevent "dangerous" human interference with the climate system. This is reflected in the objective of the convention which says that "the ultimate objective of this convention is to achieve in accordance with the relevant provisions of the convention, stabilization of greenhouse gas concentrations in the atmosphere at a level that would prevent dangerous anthropogenic interference with the climate system. "Such a level is to be achieved within a time frame sufficient to allow ecosystems to adopt naturally to climate change, to ensure that food production is not threatened and to enable economic development to proceed in a sustainable manner. The Convention defines "climate change" to mean "a change of climate which is attributed directly or indirectly to human activity that alters the composition of the global atmosphere and which is in addition to natural climate variability observed over comparable time periods" and 'climate system' has been defined to mean "the totality of the atmosphere, hydrosphere, biosphere and geosphere and their interactions".

This world convention has divided the countries into two sets. One set is called the annex- 1 countries or the industrialized countries which are responsible for most of the accumulated greenhouse gas emissions and have been asked to reduce their emissions by 6-8 percent by 2012 . The rest of the countries including India and China are called non-annex - I countries. Eastern 
European Countries, where it is said that economic meltdown has led to reduced emission by default, are called 'economies in transition' and are taken as a separate sub-category within the annex - I list.

\section{KYOTO PROTOCOL}

After five years of the adoption of the Framework Convention on Climate Change, the third conference of parties was held in Kyoto, Japan in December 1997 where in the progress made during the last five years was reviewed and future plans were chalked out by fixing strategies and objectives for the future. The outcome known as the "Kyoto Protocol' succeeded in taking certain decisions. The Kyoto protocol is an international agreement linked to the United Nations Framework Convention on Climate Change. The major feature of the Kyoto protocol is that it sets binding targets for 37 industrialized countries and the European community for reducing greenhouse gas (GHG) emissions. This amount to an average of five per cent against 1990 levels over the five-year period 2008-2012.

\section{THE DELHI DECLARATION}

In the year 2002, the eighth Conference of the parties to the United Nations Framework Convention on Climate Change was held in New Delhi which was attended by more than 170 countries. In this ten days conference which started on $28^{\text {th }}$ October 2002, the main bone of contention was whether the developing countries should take on commitment for reduction of greenhouse gas emissions beyond 2012 when the commitment period under the Kyoto Protocol comes to an end. The declaration emphasized that the United States, Russia and other developed countries which have not so far ratified the Kyoto protocol to do so at the earliest.

For the first time, the declaration linked climate change to sustainable development and talked more of adaptability of vulnerable communities to climate change rather than ways of reducing carbon emissions. But this was not acceptable to some. While the European Union and the other countries, which had committed to provide finances for the funds, insisted that activities that go to reduce or avoid emission of green house gases should also be included, the developing countries emphasized that the funds should be used more for improving their capacity to take care of the adverse impacts of the climate change.

However, despite all the differences, the general view that emerged at the end of the ministerial plenary session was that climate change significantly impacts economic development and, hence, the concern should be addressed in the context of promoting sustainable development. Many developing countries observed that adaptation to adverse effects of climate change had to be accorded priority and necessary actions taken to increase their institutional and financial capabilities to cope up with the ill-effects of climate change.

\section{THE BALI ROADMAP}

This conference was attended by more than 10,000 participants, including representatives of over 180 countries, together with observers from intergovernmental and non-governmental organizations and the media. The conference attracted a great deal of attention world over mainly because of two reasons. In the first place, just before the conference, the fourth assessment report of the intergovernmental panel on Climate Change was released and, secondly, the year 2007 was the year immediately preceding the beginning of the first commitment period under the Kyoto Protocol, i.e. 2008-2012. 


\section{THE COPENHAGEN ACCORD}

To complete the journey which started with the adoption of the Kyoto Protocol, the world leaders met again at Copenhagen in December 2009 to adopt practical measures with view to resolving the problem of climate change to the best of their abilities. Before this conference, the Fourteenth Conference of the parties (COP 14) of the United Nations Conference on Climate Change was held at Poznan, Poland from 1-12 December 2008, which was considered to be a milestone on the road to success for the processes which were launched under the Bali roadmap. The meeting had come midway between COP 13 in Bali which saw the launch of negotiations of strengthened international action on climate change and COP 15, Copenhagen, at which the negotiations are set to conclude. The poznan conference which has drawn more than 11,000 delegates representing government, industry, civil society and international organizations, constitute the halfway mark in the negotiations on an ambitious and effective international response to climate change to be agreed at Copenhagen at the end of 2009 and to take effect in 2013, the year after the first phase of the Kyoto protocol expires.

Majority of the members could not accept this United States driven accord and doubts were raised regarding the outcome of the conference as the accord did not adopt and endorse the fears of the poor countries. In fact, Copenhagen provided an opportunity to the world leaders to reach a new milestone in international co-operation on climate change. But it could not strengthen the partnership and there was no unanimous voice in resolving the issue. It was said that Copenhagen session of climate change talks ended up betraying the planet, human kind and some of the poorest regions of the world with the poorest of peoples of Africa and small island nations. It was because the rich countries, instead of making any commitments, tried to shift the burden to the developing countries. As a result, 110 heads of States who attended this conference were forced to return back to their countries without reaching any agreement.

\section{CANCUN SUMMIT}

With the bitter results of Copenhagen, in Cancun there was an opportunity to address one of the greatest challenges the world faces today in a way that acknowledges the important role that ecosystem can play in mitigating and adapting to climate change impacts. Amidst speculations, the Cancun Summit finally declared a breakthrough to the surprise of many participating countries that the Summit renewed the confidence in the United Nations process negotiations and its ability to deliver a long-term commitment and short-term actions. Putting aside their differences, the countries reached a compromise that signaled their willingness to work together in tackling climate change. The consensus include an international commitment to limit global warming to more than 2 degrees Celsius, set up new climate green fund for developing countries, support the United Nations deforestation scheme and establish a framework that will help countries adapt to changing climate.,

Issues relating to climate change forced the governments to put the matter at the top of their agenda because finding solutions has become a matter of necessity as people and communities suffer the consequences with the heating up of the planet. One thing is clear that the Cancun Summit contributed to a great extent in saving the dysfunctional United Nations negotiating process from collapse. If the countries succeed in facilitating a coordinated international approach, there is every likelihood that global actions will follow in the days to come. 


\section{CONCLUSION}

As per the fourth assessment report, more specific information is now available across a wide range of systems and sectors concerning the nature of future impacts, including some fields not covered in previous assessment. Thus, the key finding regarding the impact of climate change over the $21^{\text {st }}$ century on the system and sectors like ecosystems, food, coasts, industry, settlement and society, health and water, etc. are available. During this period, the ecosystem is expected to undergo unprecedented changes globally and with the rise in temperature, the ecosystem structure and function will be greatly affected and there will be negative impact on the biodiversity and ecosystem good and services. Although crop productivity is expected to rise marginally in mid to high latitudes, the lower latitude will experience low production. Coasts are projected to be exposed to increasing risks including coastal erosion and by 2080, many million more people than today are projected to experience floods every year due to the rise in the sea level. The industries, societies and settlements which are there in coastal and river flood plains are more vulnerable because their economies are closely linked with the climate sensitive resources. Health of the millions of people are expected to be severely affected as it is projected that several diseases will affect the health initiatives and infrastructure and economic development which are closely associated and shape the health of the population will be areas of critical concern. Similarly, water and water resources will undergo severe stress by the change in the climate.

Besides all these, the report also projects that by 2050s, freshwater availability in central, South, East and South-East Asia, particularly in large river basins will decrease, coastal areas will be at greater risk due to increased flooding from the sea. Climate change is also projected to compound the pressure on natural resources and the environment associated with rapid urbanization, industrialization and economic development. Researches also show that countries predominantly with agrarian economies will experience reducing agricultural productivity which ultimately will have a negative impact on the economic growth. This will result in lower incomes of the vulnerable populations and increase in the absolute number of people at risk of hunger.

\section{REFERENCES}

1. Agrawal, S.K. (ed.) and Garg, R.K. (ed.), Environmental Issues and Researches in India, Himanshu Publications, Udaipur (1988).

2. Bandyopadhyay, J., Climate and World Order, South Asian Publication, New Delhi (1983).

3. Barnes, James N., Let's save Antarctica, Green House Publication, Australia (1982).

4. Bhatt, S, Aviation, Environment and World Order, Radiant, New Delhi (1980).

5. Bhatt, S, Environment Protection and Sustainable Development, APH Publishing, New Delhi (2004).

6. Bigham, D. Alastair, law and Administration relating to Protection of the Environment, Oyez, London (1973).

7. Caldwell, Lynton Keith, International Environmental Policy, Affiliated East West Press, New Delhi (1991). 